BENTHAM OPEN
CrossMark
Content list available at: www.benthamopen.com/TOOPHTJ/
DOI: $10.2174 / 1874364101812010300,2018,12,300-307$

REVIEW ARTICLE

\title{
The Pattern, Presentation and Risk Factors of Ocular Trauma Among Patients Treated at Hawassa University, Referral Hospital
}

\author{
Kindie Desta Alem ${ }^{1, *}$, Samson Tesfaye Weldegiorgis ${ }^{2}$, Bekalu Getahun Agaje ${ }^{1}$ and Demoze \\ Delelegn Arega ${ }^{1}$
}

${ }^{I}$ Department of Ophthalmology and Optometry, College of Medicine and Health Sciences, Hawassa University, Hawassa, Ethiopia

${ }^{2}$ Orbis International-Ethiopia, Addis Ababa, Ethiopia

Received: May 1, 2018

Revised: August 14, 2018

Accepted: October 16, 2018

\section{Abstract:}

Background:

Ocular trauma is a significant public health problem which may lead to permanent visual impairment. Being preventable, the visual impairment can occur at any age in either sex and has significant socioeconomic burden especially in developing countries.

\section{Objective:}

To assess the pattern, presentation and risk factors of ocular trauma in patients treated at Hawassa University, Referral Hospital, South Ethiopia

\section{Methods:}

The study was conducted from August 01, 2014 to July 31, 2015, and all patients who visited Hawassa University, Referral Hospital for ocular trauma were included in the study. Data entry and analysis was done using SPSS version 20 and the descriptive and analytic statistics were carried out.

\section{Results:}

A total of 335 patients were included into the study. Ocular trauma was observed mostly in children (65.67\%) and rural dwellers (76.12\%). Assault trauma and surgery, secondary to trauma, were associated with open globe injury $(\mathrm{P}=0.021, \mathrm{AOR}=43.17$ and $\mathrm{P}$ $=0.006, \mathrm{AOR}=25.67$, respectively). The corneal tear was the most frequently observed finding $(59.70 \%)$. Most of the patients $(>90 \%)$ presented after 6 hours from time of ocular trauma and the treatment was commenced also after 6 hours in $>95 \%$ of them. Among all patients included in the study, $59.71 \%$ of them were with visual acuity of $<3 / 60$ at presentation.

\section{Conclusion:}

Ocular trauma was high in males, children, rural dwellers and low income families and most of the patients $(>90 \%)$ presented after 6 hours from time of ocular trauma.

Keywords: Ocular, Trauma, Pattern, Presentation, Risk Factor, Hawassa, Ethiopia.

\section{INTRODUCTION}

The eye is the third most common organ affected by trauma, after hands and feet. But it represents only $0.27 \%$ of the total body surface area and $4 \%$ of the facial area [1].

\footnotetext{
* Address correspondence to this author at the Department of Ophthalmology and Optometry, College of Medicine and Health Sciences, Hawassa University, Hawassa, Ethiopia; Tel: +2519 1368 3959; E-mail: kindudiaopt@gmail.com
} 
Ocular trauma is a significant preventable public health problem especially in developing countries and it may lead to permanent visual impairment [1 - 7]. Ocular trauma may occur at any age in either sex [1, 4], especially among pediatric and elderly population [1]. According to both hospital and population based studies, males are more affected by ocular trauma $[1,2,4,7]$.

As estimates of World Health Organization (WHO), the global annual incidence of ocular trauma is around 55 million [3, 6, 8]. Globally, blindness in 1.6 million people is due to ocular trauma [1, 7 - 9].

Corneal tear, sclera tear and lens damage were the most frequently observed morbidities of ocular trauma and lid and canalicular laceration, uveal prolapse, anterior chamber abnormality, retinal detachment and optic nerve avulsion were also repeatedly observed $[1,2,8,10,11]$.

Majority of the patients were presented to eye health facilities after 24 hours from time of trauma [1 - 3, 5, 6, 10, 12]. Patients reported within $24 \mathrm{hrs}$ of eye injury showed better visual outcome after treatment than patients reported after $24 \mathrm{hrs}$ [2].

Ocular trauma has a direct and an indirect impact on the social and economic importance of human being and millions of dollars will be lost annually due to visual impairment caused by ocular injury $[1,5,6]$.

In a study conducted in Grarbet, Ethiopia, most of the patients $(67.6 \%)$ were presented for the treatment of ocular trauma on the third day and later [5]; however, no studies had been carried out on the pattern, presentation and risk factors of ocular trauma in the study area. So, in view of public health importance, this study will provide information for respective stack holders for planning and implementing preventive and curative measures.

\section{MATERIALS AND METHODS}

Hospital based study was conducted from August 01, 2014 to July 31, 2015 in Hawassa University, Referral Hospital, Ophthalmology Department. Hawassa University, Referral Hospital is found in Hawassa town, South Ethiopia, about $275 \mathrm{Kms}$ from Addis Ababa, the capital city of Ethiopia. The tertiary eye care center was established in 2005 by the support of Orbis International-Ethiopia. This tertiary eye care center serves approximately 14 million people of a catchment area. With pediatrics, retina and binocular vision and refraction clinics comprehensive eye care services are being provided in the center, both in outpatient and inpatient departments. There are 3 ophthalmologists, 10 optometrists, 1 ophthalmic officer, 1 cataract surgeon, 8 ophthalmic nurses and 3 primary eye care workers providing the service.

The study included all patients who visited Hawassa University, Referral Hospital, Ophthalmology Department for ocular trauma from August 01, 2014 to July 31, 2015. Patients who were unable/ unwilling to respond for the questions were excluded from the study.

The dependent variable was ocular trauma and the independent variables were socio-demographic data (sex, age, residence, religion, occupation, level of education, income), the distance from hospital, place where trauma occurred, type of object that causes trauma, occasion of trauma, time of presentation, time of intervention and Visual Acuity (VA) (at presentation and after treatment).

Data abstraction form and questions were developed based on the literature, to obtain information on sociodemographic characteristics and other factors. This form was pretested in 5\% of the sample and modified accordingly.

The data collection was performed using questioner and through observation. There were five optometrists, four ophthalmic nurses and one ophthalmic officer for data collection and one ophthalmologist for supervision.

The collected data was checked out for the completeness, accuracy and clarity by principal investigator and supervisor on daily basis. The supervisor checked the filled data daily and amendments were done at the spot. Data clean up, double entry and cross-checking were done before analysis.

After coding, the data was entered and analyzed using SPSS version 20 . The descriptive statistics, bivariate and multivariate logistic regressions were carried out. The variables that were found being significant $(p \leq 0.2)$ in bivariate logistic regression were entered into multivariate logistic regression model. A P-value $<0.05$ was considered statistically significant.

Before conducting the study, ethical clearance was obtained from the Institutional Review Board of Hawassa University, College of Medicine and Health Sciences. Official permission from the hospital was obtained. Though people were not either exposed to unnecessary risk or inflicted harm during primary data collection, an oral and written 
informed consent of each participant was taken after explaining the purpose of the study. For children, the consent was done through their legal representatives. Confidentiality of the information was maintained thoroughly by excluding names as identification in the questioner and data abstraction form and keeping their privacy during data collection. Their charts were returned to chart room soon after collecting the necessary data. No one had access to the non-coded data except investigators, data collectors and supervisor due to responsibilities associated with the study.

\section{RESULTS}

A total of 335 patients ( $73 \%$ males and $27 \%$ females) presented with ocular trauma were examined and interviewed using structured questioner. From 2 months to 64 years old patients visited during the study period were included in the study. Ocular trauma was occurred mostly in children $(65.67 \%)$, followed by adolescents $(25.37 \%)$. The occurrence of ocular trauma is relatively low as the age increases (Fig. 1).

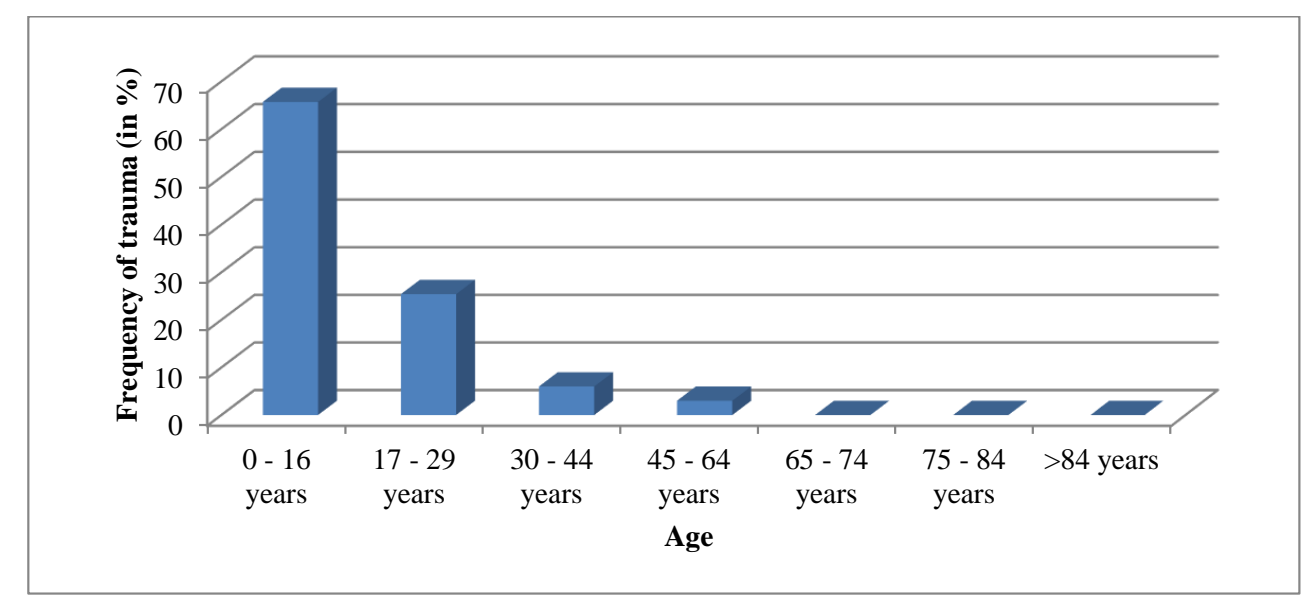

Fig. (1). Distribution of ocular trauma in age among patients treated at Hawassa University, Referral Hospital, from August 01, 2014 to July $31,2015(\mathrm{~N}=335)$.

Ocular trauma was frequently observed in urban residents $(76.1 \%, \mathrm{n}=255)$ as compared to rural dwellers $(23.9 \%$, $\mathrm{n}=80)$. From all patients visited for ocular trauma, most of them $(38.81 \%)$ were Islamic religion followers, followed by Protestants (35.82\%). The occurrence of trauma was frequently observed in students (41.79\%) (Fig. 2).

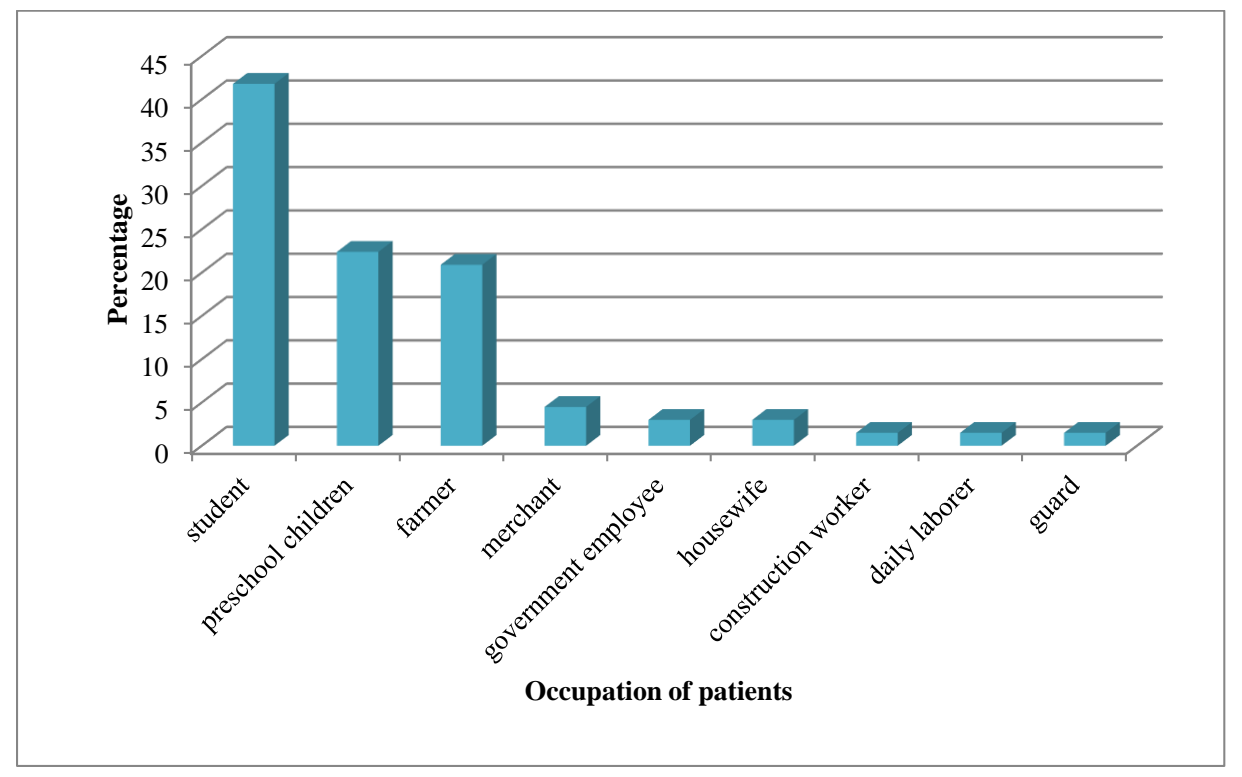

Fig. (2). Occupation and ocular trauma distribution of patients treated at Hawassa University, Referral Hospital, from August 01, 2014 to July $31,2015(\mathrm{~N}=335)$. 
Most of the patients who visited the hospital for ocular trauma had dropped their education at primary school $(59.70 \%, \mathrm{n}=200)$ and $28.4 \%(95)$ were illiterates. No report of ocular trauma of first degree holders and above. Nearly $87 \%$ of patients were from a family whose household monthly income is up to 3,000 Ethiopian birr (177\$) and the rest were from a family whose household monthly income is $>3,000$ Ethiopian birr (Table 1).

Table 1. Monthly household income of patients treated for ocular trauma at Hawassa University, Referral Hospital, from August 01, 2014 to July 31, $2015(\mathrm{~N}=335)$.

\begin{tabular}{|c|c|}
\hline Monthly household income (in birr) & Frequency (\%) \\
\hline $0-499$ & $50(14.9)$ \\
\hline $500-999$ & $85(25.4)$ \\
\hline $1000-1999$ & $75(22.4)$ \\
\hline $2000-2999$ & $80(23.9)$ \\
\hline $3000-5000$ & $25(7.5)$ \\
\hline$>5000$ & $20(6.0)$ \\
\hline Total & $\mathbf{3 3 5 ( 1 0 0 )}$ \\
\hline
\end{tabular}

The health facility was found in $<20 \mathrm{Km}$ for $90.63 \%$ (304) patients, in $20-100 \mathrm{Km}$ for $7.81 \%$ (26) patients and in $>100 \mathrm{Km}$ for $1.56 \%$ (5) patients from their residence area. But, about $80 \%$ health facilities where the patients visited for ocular trauma were not providing eye care services. From $20 \%$ health facilities where eye care services were available; in $38.46 \%$ (26) of them only patching service was provided, in $30.77 \%$ (21) of them medical treatment was given and in $23.08 \%(16)$ of them nothing was done.

The occurrence of ocular trauma at mid day and at evening was found to be proportional $(41.79 \%$ each) and at morning it was $13.43 \%$ as well as at night it was $2.99 \%$. In $31.34 \%$ (105) patients, the trauma occurred at street (Table 2). From a total females who visited the hospital, $50.0 \%$ of trauma occurred at home and there was no a trauma occurrence at farm place. On the other hand, from total males, proportional trauma occurrence was observed both at home and at farm place (18.4\% each).

Table 2. The place where ocular trauma was occurred for patients treated at Hawassa University, Referral Hospital, from August 01, 2014 to July 31, $2015(\mathrm{~N}=335)$.

\begin{tabular}{|c|c|}
\hline The place where ocular trauma was occurred & Frequency (\%) \\
\hline Street & $105(31.3)$ \\
\hline Home & $90(26.9)$ \\
\hline Compound & $80(23.9)$ \\
\hline Farm place & $45(13.4)$ \\
\hline Public building & $15(4.5)$ \\
\hline Total & $\mathbf{3 3 5}(\mathbf{1 0 0})$ \\
\hline
\end{tabular}

In 47.76\% (160) patients ocular trauma was caused by wood/ stick (Fig. 3). About 87\% (291) of trauma occurred accidentally and $13 \%(44)$ of them by assault. Assault trauma was associated with open globe injury $(P=0.021, \mathrm{AOR}=$ 43.167).

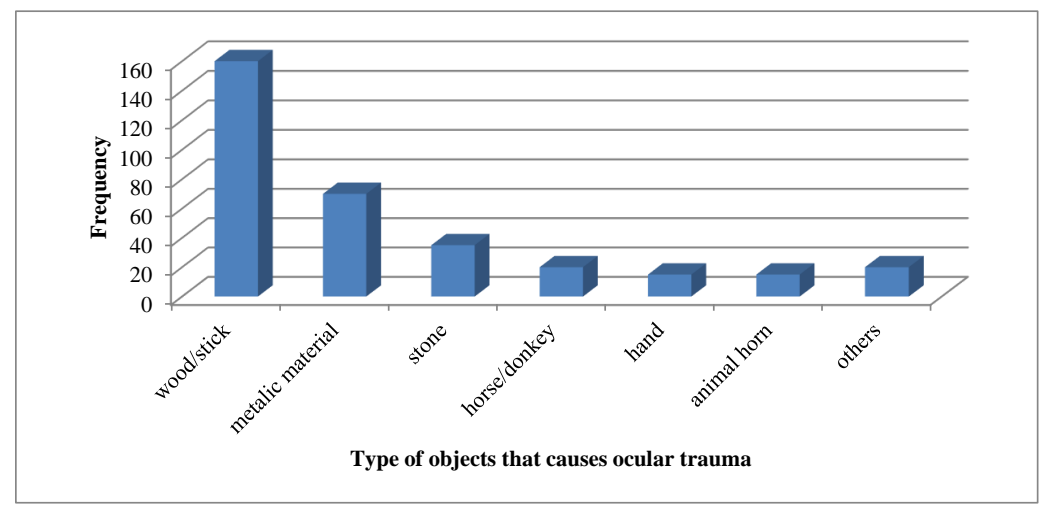

Fig. (3). Distribution of ocular trauma causing objects of patients treated at Hawassa University, Referral Hospital, from August 01, 2014 to July $31,2015(\mathrm{~N}=335)$. 
Most of the patients $(71.64 \%, \mathrm{n}=234)$ have travelled $>100 \mathrm{Km}$ to get a treatment at Hawassa University, Referral Hospital; $19.40 \%$ (65) patients have travelled 20-100 Km and 8.96\% (30) patients have got a treatment travelling only $<$ $20 \mathrm{Km}$. Most of the ocular injuries were open globe (65.67\%) (Table 3).

Table 3. Distribution of ocular injury types in patients treated at Hawassa University, Referral Hospital, from August 01, 2014 to July 31, $2015(\mathrm{~N}=335)$.

\begin{tabular}{|c|c|c|c|}
\hline \multicolumn{3}{|c|}{ Type of injury } & Frequency (\%) \\
\hline \multirow{4}{*}{ Open globe injury } & \multirow{3}{*}{ Laceration } & Penetrating globe injury & $145(43.3)$ \\
\hline & & IOFB & $25(7.5)$ \\
\hline & & Perforating globe injury & $40(11.9)$ \\
\hline & & oture & $10(3.0)$ \\
\hline \multirow{2}{*}{ Closed globe injury } & & tusion & $93(27.8)$ \\
\hline & \multicolumn{2}{|c|}{ Lamellar laceration } & $22(6.6)$ \\
\hline \multicolumn{3}{|c|}{ Total } & $335(100)$ \\
\hline
\end{tabular}

All ocular structures, from anterior to posterior segment, were affected by trauma. Among all (335) cases, corneal tear was the most frequently observed case (59.70\%), followed by lens damage and anterior chamber abnormalities (25.37\% each) (Table 4).

Table 4. Patterns of ocular trauma and their distribution among patients treated at Hawassa University, Referral Hospital, from August 01, 2014 to July 31, $2015(\mathrm{~N}=335)$.

\begin{tabular}{|c|c|}
\hline Pattern of ocular trauma & Frequency (\%) \\
\hline Corneal tear & $200(59.7)$ \\
\hline Lens damage & $85(25.4)$ \\
\hline Anterior chamber abnormality & $85(25.4)$ \\
\hline Uveal prolapse & $75(22.4)$ \\
\hline Eyelid damage & $40(11.9)$ \\
\hline Scleral tear & $35(10.5)$ \\
\hline Corneal FB & $20(6.0)$ \\
\hline Sub-conjunctival haemorrhage & $20(6.0)$ \\
\hline Others & $35(10.5)$ \\
\hline
\end{tabular}

FB $=$ Foreign Body

In most of the patients, more than three ocular structures were affected by trauma. Out of 335 patients, in 25 of them; corneal tear, anterior chamber abnormality, uveal prolapse and lens damage were observed.

Majority of patients $(92.54 \%, n=310)$ who encountered ocular trauma were presented to Hawassa University, tertiary eye care center after six hours from time of trauma and $47.76 \%$ (160) of them presented to the hospital after three days from time of trauma (Fig. 4).

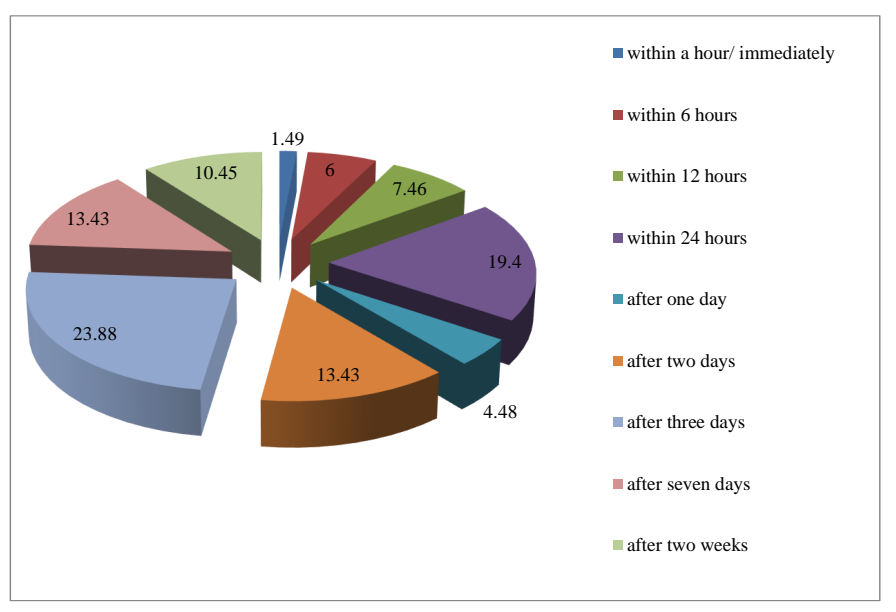

Fig. (4). Presentation time of patients to Hawassa University, Referral Hospital after ocular trauma, from August 01, 2014 to July 31 , $2015(\mathrm{~N}=335)$. 
The reason for delayed presentation assumed that treatment in health centers is enough (34.33\%) and the distance from referral hospital is $(29.85 \%)$ (Table 5). But there was no variable associated with the time of presentation.

Table 5. The reason for delay in presentation of patients who treated at Hawassa University, Referral Hospital, from August 01, 2014 to July 31, $2015(\mathrm{~N}=335)$.

\begin{tabular}{|c|c|}
\hline The reason for delay & Frequency (\%) \\
\hline Assuming treatment in health center is enough & $115(34.3)$ \\
\hline Distance from referral hospital & $100(29.9)$ \\
\hline Shortage of money & $45(13.4)$ \\
\hline Lack of awareness & $20(6.0)$ \\
\hline Unavailability of transportation & $10(3.0)$ \\
\hline Others & $30(9.0)$ \\
\hline
\end{tabular}

Most of the patients $(95.52 \%)$ who presented for ocular trauma were intervened after 12 hours from the time of trauma. Only $1.49 \%$ of the total patients were treated immediately/ within 6 hours. Delayed presentation due to the distance from eye care center, lack of awareness and shortage of money were the common reasons for delayed intervention (76.12\%). Ocular surgery secondary to trauma was performed in 50.8\% (170) patients and among all; corneal tear repair was the most frequently performed surgery $(64.7 \%)$, followed by crystalline lens extraction/ lens fragment washout (14.70\%) (Fig. 5). Surgery, secondary to trauma, was associated with open globe injury $(P=0.006$, $\mathrm{AOR}=25.67)$

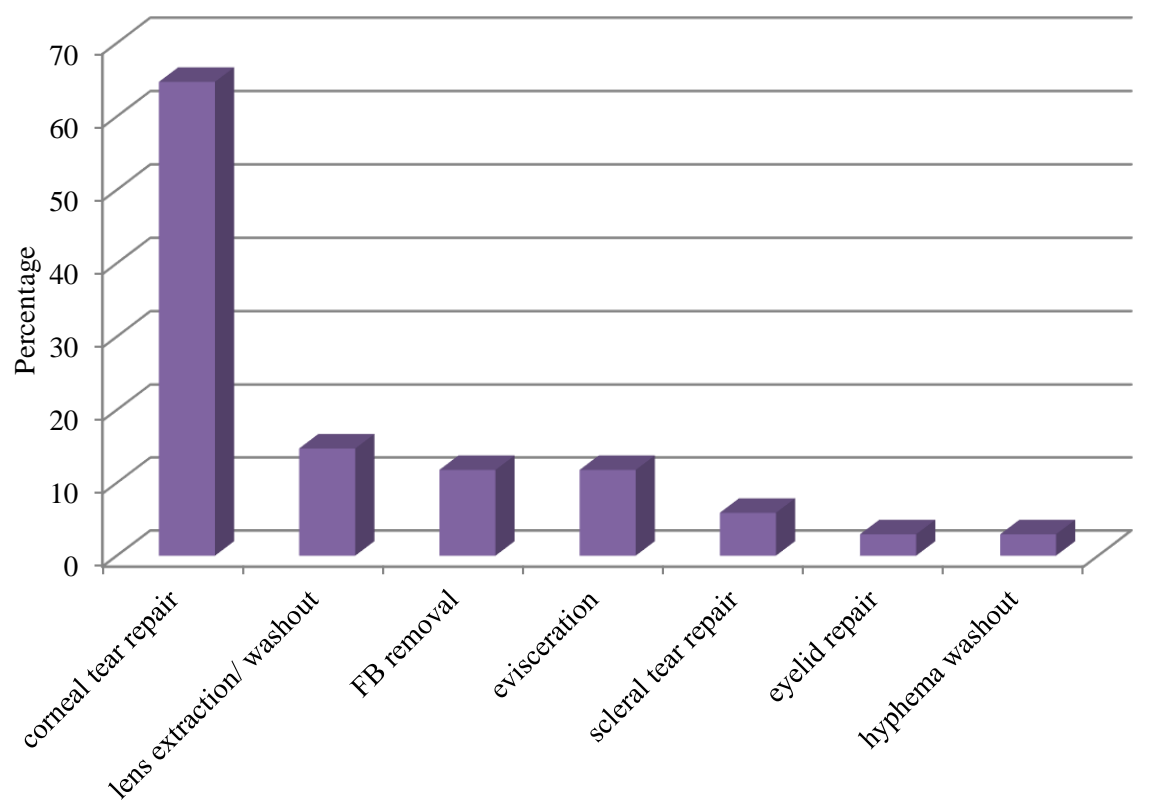

Surgery secondary to trauma

Fig. (5). Type of sugery secondary to trauma among patients treated at Hawassa University, Referral Hospital, from August 01, 2014 to July $31,2015(\mathrm{~N}=335)$.

The presentation VA was $6 / 6$ only for $4.48 \%$ (15) patients and it was under blindness category $(\mathrm{VA}<3 / 60)$ for $59.71 \%$ (200) patients. At first day, after treatment, the VA was $6 / 6$ only for $7.46 \%$ (25) patients and it was under blindness category $(\mathrm{VA}<3 / 60)$ for $47.76 \%(160)$ patients.

\section{DISCUSSION}

The result showed that the occurrence of ocular trauma is high in males $(73.1 \%)$ and this is supported by other studies conducted around the globe; in Peshawar, Pakistan males accounted 80\%, in Lahore, Pakistan-75\%, in Nepal-69.3\%, in Uttarakhand, India, male to female ratio-1.93:1 and in Grarbet, Ethiopia the male to female ratio was $3: 1[3,5,8-10]$. This might be due to the reason that males are mainly engaged in outdoor activities where trauma will be highly encountered. 
Among patients presented for ocular trauma, children (65.67\%) followed by adolescents (25.37\%) had accounted more than $80 \%$ and this is in agreement with other studies; Pakistan, <30 years old-69\% (Peshawar), 18-29 years old-31\% (Lahore); Kashmir valley, 16-26 years old-75\% [8, 10, 13].

Majority of the patients reported for ocular trauma in this study were rural dwellers (76.12\%) and similarly on the study conducted in western Nigeria, more than half (52.53\%) patients were from rural area [1].

In this study, open globe injury has accounted $65.67 \%$ and closed globe injury was $32.84 \%$. Closed globe injury is in line with the finding of Uttarakhand, India (31.9\%) [6]. Penetrating globe injury was the highest finding among open globe injuries (43.28\%) and this finding was reported as $12.1 \%$ in Nigeria [1]. Globe rupture of the present study is $2.99 \%$, but in a study conducted in Egypt, it was found to be $31.4 \%$ [12].

In this study, corneal tear was the most frequently observed case (59.70) which is much higher as compared to a study done in western India (15.2\%) [2]. Anterior chamber abnormality was $25.37 \%$ and this finding was higher in Pakistan; Jinnah $(84 \%)$ and Peshawar $(>50 \%)$ [8, 10]. In contrast, the findings were lower in Nigeria (5.9\%) and western India (8.29\%) [1, 2]. Uveal prolapse was $22.39 \%$ in this study, but it was $10 \%$ of all cases in Jinnah, Pakistan [8]. About $25 \%$ lens damage was observed in this study and the higher as well as the lower values were noticed in other studies $[2,8,10]$. The discrepancies might be due to the differences in the type of object that causes ocular trauma.

Only $1.49 \%$ patients were presented in the hospital within hour/ immediately, but in a study of Lahore, Pakistan, $23 \%$ of patients were reported within one hour after ocular trauma [8]. In a study conducted in Nigeria and Lahore, Pakistan, similar numbers of patients $(38 \%)$ were presented for ocular trauma within 24 hours and in Uttarakhand, India $52.27 \%$ patients were reported within this time. But in our study, only $19.4 \%$ patients were presented within 24 hours $[1,3,8]$. From $1^{\text {st }}$ to $7^{\text {th }}$ days, $41.79 \%$ patients were reported for ocular trauma in this study, but in Nigeria, $32.5 \%$ patients and in Uttarakhand, India, $12.7 \%$ patients were reported in the same period [1, 6]. After 7 days, $23.8 \%$ patients were presented for ocular trauma and in this time $6 \%, 12.7 \%, 29.5 \%$ and $63.61 \%$ patients were reported in Egypt, India, Nigeria and Pakistan, respectively $[1,6,10,12]$. The variations in presentation time might be due to the differences in distance from eye care center, poverty, awareness and transportation system across the countries.

From 335 patients visited the hospital for ocular trauma, $95.52 \%$ of them reported availability of health facilities around their area, but $79.69 \%$ of these facilities were not providing eye care service. And hence, $71.64 \%$ of patients travelled $>100$ kilometers to get eye care service in Hawassa University, Referral Hospital. Also, 19.40\% of patients have crossed 20-100 kilometers for Hawassa, but only 8.96\% patients were from $<20$ kilometers. On contrary to this, the majority of patients were from nearby in other studies; in Nigeria, $61.4 \%$ patients were from $<20$ kilometers, $21.2 \%$ patients were from 20-50 kilometers, 12.95 patients were from 50-100 kilometers and 4.5\% patients were from $>100$ kilometers, in Grarbet, Ethiopia, 44.4\% patients were from $<20$ kilometers and 55.6\% patients were from $>20$ kilometers $[1,5]$. This might be due to the variations in availability of eye care centers/ specialized eye care centers around.

The common cause of ocular trauma in this study was wood/ stick (47.76\%), but in other studies road traffic accident (western India-38\%, Uttarakhand, India-32.7\% and 26.66\%) and stone (Kashmir valley-48.3\%) were the main causes of ocular trauma $[2,3,6,13]$.

At presentation, $4.48 \%$ patients were with VA of $6 / 6$ and $59.71 \%$ were with VA of $<3 / 60$ in our study. Similarly, in a study conducted in Uttarakhand, India 56.5\% patients were presented with VA of $<3 / 60$ [6]. Many of our patients have missed post intervention follow ups and due to this post intervention visual outcome could not be analyzed.

\section{CONCLUSION}

The ocular trauma was high in males, children, rural dwellers and low-income families and the common object that causes the trauma was wood/ stick. Most of the patients ( $>90 \%)$ presented after 6 hours from time of ocular trauma and the treatment was commenced also after 6 hours in $>95 \%$ of them. Most of the patients $(>70 \%)$ were from a distance of $>100$ kilometers from hospital. The cornea was the most commonly affected ocular structure by trauma.

Among variables entered into multivariate logistic regression; surgery, secondary to trauma, was associated with open globe injury $(P=0.006$, AOR $=25.67)$. Assault trauma was also associated with open globe injury $(P=0.021$, $\mathrm{AOR}=43.17)$. 


\section{CONSENT FOR PUBLICATION}

A written informed consent and assent was obtained from all patients when they were enrolled.

\section{CONFLICT OF INTEREST}

The study was sponsored by Orbis International-Ethiopia and authors declare no conflict of interests in this work.

\section{ACKNOWLEDGEMENTS}

We would like to express our heartfelt gratitude to Zelalem Mekonnen, Orbis project coordinator at Hawassa University, for her unreserved support. Also, we want to extend our appreciation to Orbis International-Ethiopia for its financial support and we would like to express our great thanks to the department of ophthalmology and optometry colleagues for their help during research progress.

Authors' contributions: Kindie Desta has made substantial contribution to performing research/study, analyzing the data and writing the paper; Samson Tesfaye has been involved in analyzing the data and fund acquisition; Bekalu Getahun has been involved in original draft preparation and writing the paper; Demoze Delelegn has made substantial contribution to designing the research and analyzing the data.

\section{REFERENCES}

[1] Omolase CO, Omolade EO, Ogunleye OT, Omolase BO, Ihemedu CO, Adeosun OA. Pattern of ocular injuries in owo, Nigeria. J Ophthalmic Vis Res 2011; 6(2): 114-8. [PMID: 22454720]

[2] Tejas D, Chinmayi V, Suhani D, Shiv M. Pattern of ocular injury in pediatric population in western India. NHL J of Med Sci July 2013; 2(2)

[3] Dhasmana R, Bahadur H, Jain K. Profile of ocular trauma in Uttarakhand, A hospital based study. Indian J Comm Health 2012; 24(4) Oct. 2012-Dec

[4] Khurana A. Comprehensive ophthalmology. $4^{\text {th }}$. New Delhi, India: New age international (p) limited 2007.

[5] Zelalem A. Pattern of ocular trauma seen in grarbet hospital, butajira, central ethiopia. Ethiop J Health Dev 2011; 25(2)

[6] Govind S, Chandra P, Swati G, Vijay J. Pattern of ocular trauma in tertiary care hospital of kumaon region, Uttarakhand. J Indian Acad Foren Med 2013; 35(2)

[7] MacEwen CJ. Ocular injuries. J R Coll Surg Edinb 1999; 44(5): 317-23. [PMID: 10550957]

[8] Tehmina J, Nadeem H, Uzma H, Haroon T, Samina J. Pattern of presentation and factors leading to ocular trauma. Pak J Ophthalmol 2011; 27(2)

[9] Kinderan YV, Shrestha E, Maharjan IM, Karmacharya S. Pattern of ocular trauma in the western region of Nepal. Nepal J Ophthalmol 2012; 4(1): 5-9.

[http://dx.doi.org/10.3126/nepjoph.v4i1.5843] [PMID: 22343989]

[10] Babar TF, Khan MT, Marwat MZ, Shah SA, Murad Y, Khan MD. Patterns of ocular trauma. J Coll Physicians Surg Pak 2007; 17(3): 148-53. [PMID: 17374300]

[11] Lee CH, Su WY, Lee L, Yang ML. Pediatric ocular trauma in Taiwan. Chang Gung Med J 2008; 31(1): 59-65. [PMID: 18419054]

[12] Soliman MM, Macky TA. Pattern of ocular trauma in Egypt. Graefes Arch Clin Exp Ophthalmol 2008; $246(2): 205-12$. [http://dx.doi.org/10.1007/s00417-007-0720-4] [PMID: 18071733]

[13] Khan S, Maqbool A, Abdullah N, Keng MQ. Pattern of ocular injuries in stone pelters in kashmir valley. Saudi J Ophthalmol 2012; 26(3): 327-30.

[http://dx.doi.org/10.1016/j.sjopt.2012.04.004] [PMID: 23961014]

\section{(C) 2018 Alem et al.}

This is an open access article distributed under the terms of the Creative Commons Attribution 4.0 International Public License (CC-BY 4.0), a copy of which is available at: (https://creativecommons.org/licenses/by/4.0/legalcode). This license permits unrestricted use, distribution, and reproduction in any medium, provided the original author and source are credited. 